\title{
Mechanical testing and modelling of the Universal 2
}

\section{implant}

\author{
M.K. Gislason ${ }^{1,2}$, E. Foster², D. Main², G Fusiek², P Niewczas², M Bransby- \\ Zachary ${ }^{3}$, D.H. Nash ${ }^{2}$
}

1. Department of Biomedical Engineering, School of Engineering and Technology, University of Reykjavik, Reykjavik, Iceland

2. Faculty of Engineering, University of Strathclyde, Glasgow, UK

3. Southern General Hospital, Glasgow, UK

*Corresponding author. Department of Biomedical Engineering, School of Engineering and Technology, University of Reykjavik, Reykjavik, Iceland, Menntavegur 1, 101 Reykjavik, Iceland

Tel.: +354 599 6344; fax: +354 5996201

E-mail address: magnuskg@ru.is

\section{$\underline{\text { Abstract }}$}

Understanding the load mechanics of orthopaedic implants is important to be able to predict their behaviour in-vivo. Much research, both mechanical and clinical, has been carried out on hip and knee implants, but less has been written about the mechanics of wrist implants. In this paper, the load mechanics of the Universal 2 wrist implant have been measured using two types of measuring techniques, strain gauges and Fibre Bragg Grating measurements to measure strains. The results were compared to a finite element model of the implant. The results showed that the computational results were in good agreement with the experimental results. Better understanding of the load mechanics of wrist implants, using models and experimental results can catalyse the development of future generation implants.

Keywords: Wrist implants, finite element modelling, strain measurements, mechanical testing 
$\underline{\text { Introduction }}$

34

35 The design of wrist implants has varied greatly in the last decades. The Swanson wrist

36 implant was one of the first implants to gain a commercial success in the US and was based

37 on the concept of a silicone spacer aimed to increase stability in the radiocarpal joint [1].

38 Fixation was achieved through a proximal radial stem and a distal stem passing through the capitate and into the third metacarpal. With time, a number of fractures on the distal stem were reported [2], leading to a revision of the mechanical design. The next generation implant designs were the Volz [3], and the Meuli [4] implants which demonstrated considerable changes in the overall design compared to the Swanson and used a metal stem made from

$43 \mathrm{CoCr}$ and a ball in socket articulations. Other designs followed such as the semi-constrained Trispherical, the Guépar and the biaxial prosthesis which all then were eventually removed from the market [5].

In 2005 Shepherd and Johnston [6] evaluated the design criteria for a total wrist prosthesis in terms of loading conditions, contact stresses, wear rate amongst others. The challenges that engineers face in terms of the overall design of a wrist implant are mainly the small area to fixate the implant components to the bone, in particular in the distal attachment, and the variability of the loads and range of motion. In lower limb implants, such as the knee and the hip, the loading conditions are well defined in terms of gait, ascending, descending stairs etc. The load cases on the upper limb are more ambiguous where gripping, lifting and pushing with the wrist in multiple different positions can occur during activities of daily living. It has been shown that during a key turn action in rheumatoid arthritic patients, the average resultant load on the index finger is $13.9 \mathrm{~N}$ [7]. Using a biomechanical model, Fowler and 
57 Nicol [7], also calculated the joint contact forces on an MCP implant to find that during the same key turn action, the contact force was on average $182.5 \mathrm{~N}$, which represents the load of a single digit, namely the index finger. Kanellopoulos [8] measured external forces on all fingers during gripping with the wrist in various different positions for young healthy subjects of both sexes and reported that the resultant force on the index finger was on average 23.1 N. It has also been reported [9] that the load distribution between the fingers was in the ratios 35:30:21:14 between the index, long, ring and little finger respectively. Internal loads acting over all five digits were calculated [9] with the wrist in neutral gripping position, using the biomechanical model presented by Fowler and Nicol [7] to find an average resultant force of $1472 \mathrm{~N}$ (standard deviation of $320 \mathrm{~N}$ ) acting on the MCP joints. Chadwick and Nicol [10] reported overall wrist joint reaction forces exceeding $2000 \mathrm{~N}$, during the horizontal power grip in healthy young subjects. Fok and Chou [11] concluded that the joint reaction forces on the MCP joint could be up to 30 times higher than the external forces applied to the fingers. Although a few studies of the biomechanical modelling of the hand exist, there are large variations in the load application to the hand, but all indicate that during gripping the forces through the wrist can be on the order of 1-2 times bodyweight which is a considerably high load given the small size of the joints in the hand and wrist.

Given the success of the hip and knee implants over the years, patient expectations have grown, to have a pain free and a stable joint after total joint arthroplasty. The design and manufacturing process of a joint implant is subjected to vigorous standards from regulating authorities [12]. Development of wrist implants is ongoing and since the introduction of the

79 Swanson implant, many designs have been marketed and some with limited success. Third generation implants like the Universal, the ReMotion and the Maestro are now popular in 
proximal and the distal aspect which has been shown by Grosland et al [13] to have an improved property compared to a toroidal shape in terms of stability. All are constructed with a metal stem, a polyethylene spacer and a distal carpal metal plate with screws. Different design aspects can be seen between various implants currently available. This difference can, in particular, be seen between the Universal 2 and the ReMotion on one side and the Maestro on the other. The Universal 2 and the ReMotion have the polyethylene component attached to the distal component in a convex configuration, whereas the Maestro implant has the polyethylene component attached to the proximal stem in a concave configuration, thus resembling more the geometrical features seen in the hip and the knee.

91

The finite element method is a powerful tool to calculate in vivo stresses on the structural aspect of the human body and has been used with much success to predict loading behaviour on hip and knee implants $[14,15]$. It is widely used during design processes of various components and can be of great importance for orthopaedic implants where experimental work can be difficult to carry out [16]. Little has been written about modelling of the wrist implants. McCullough [17,18] studied the contact area of various wrist implants under simulated muscle loading from the 3 extensor muscles (extensor carpi radialis longus/radialis brevis/ulnaris) and the 2 flexor muscles (flextor carpi radialis/ulnaris) and demonstrated that the Universal 2 implant had greater contact area than the Biax and the Universal total wrist implant as well as lower maximum stress. Bajuri et al [19] published one of the first finite element model of the implanted wrist, focussing on the ReMotion implant. Otherwise little has been published on the mechanical properties of the total wrist implants where many studies have looked at the mechanics of total hip and total knee implants. 
106 The presented study, demonstrates validation work carried out on the Universal 2 wrist

107 implant and compares with a finite element model created of the implant. Two different types

108 of strain measurements were carried out, firstly using strain gauges and secondly using Fibre

109 Bragg Grating to measure the strain inside the prosthesis. Fibre Bragg grating is an

110 established technique in determining strains in various application, given its light weight,

111 flexibility and resistance to corrosion to name a few [20] and has previously been used to

112 measure the strains in bone tissue [21] and contact pressure in total knee arthroplasty [22].

114 Validation work is difficult to carry out on the wrist joint, as the joint is small and applying

115 measuring devices requires a high degree of joint exposure which will destroy the stabilizing

116 effects of the soft tissue around the joint, thus making it prone to buckling during a uniaxial

117 compression test. In vivo, the load cases on the total wrist implant are more complex than

118 simple uniaxial compression, but by carrying out measurements using a simplified loading

119 scenario and compare to FE model predictions, it will give indications about the mechanical

120 behaviour under more complex load cases. That would be the first step in validating the finite

121 element models. In the presented study, the Universal 2 implant from Integra was used, as it 122 is one of the leading implant used in the UK and the US.

\section{Methods}

\section{$126 \quad$ Finite element model}

127 A Universal 2 wrist implant in size large was obtained. It consisted of 3 components: a radial component, a carpal component and a polyethylene component. All three components were scanned using an industrial scanner at the Advanced Forming Research Centre at the

130 University of Strathclyde in Glasgow where the geometry was reversed engineered into an 
131 STL model. The STL geometry was imported into Mimics (Materialise) where the three components manually aligned with each other and virtually inserted into the radius bone. The components were surface meshed using a semi-automated mesher and imported into Abaqus

134 (v.6.11). There the surface meshes were converted into 10 node tetrahedral elements, of type

135 C3D10M. The total number of elements was 246.888 for the full model. The total volume was $10616 \mathrm{~mm}^{3}$, resulting in element density of 23.3 elements $/ \mathrm{mm}^{3}$. Interaction between the components was defined either using a surface to surface contact formulation or tie constraints. The connections between the components are listed in Table 1.

\begin{tabular}{|l|l|}
\hline Components & Type of contact \\
\hline Distal part - polyethylene & Tie \\
\hline Polyethylene - radial part & Surface to surface contact \\
\hline Radial part - radius bone & Tie \\
\hline
\end{tabular}

Table 1: Interaction between the components

141 Loading was applied as uniaxial compressive load to the distal component, simulating

142 compressive forces ranging between 0 and $2000 \mathrm{~N}$ [10], which can be expected during

143 gripping motion. Figure 1 shows the finite element models. 


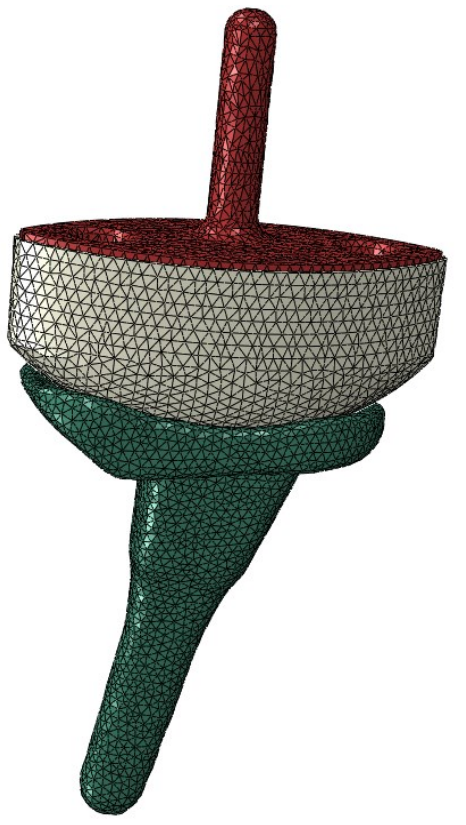

Figure 1a - Finite element model of the Universal 2 implant

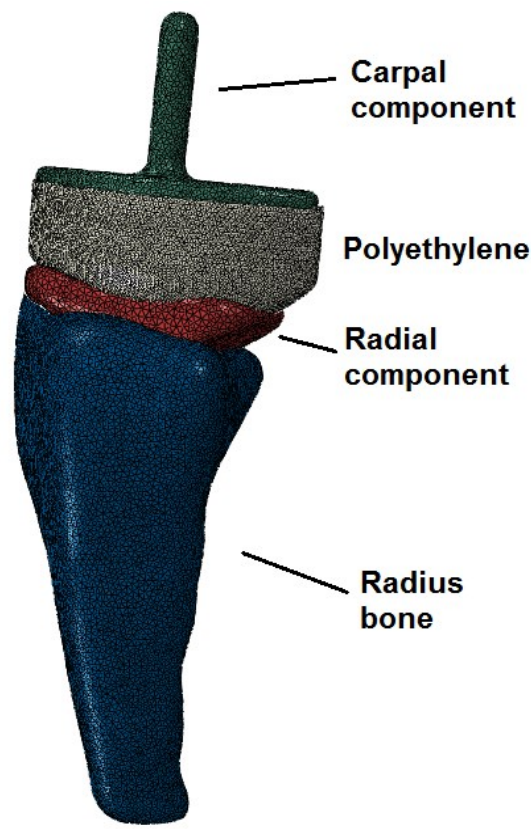

Figure $1 b-$ Prosthesis inserted into the radius bone

146 The loading was applied as a pressure over the distal surface of the carpal component. Matlab

147 procedure was written to estimate the surface area by summing up individual areas from each

148 element located at the surface. The overall area was calculated as $349.6 \mathrm{~mm}^{2}$ and a pressure

149 of $5.72 \mathrm{MPa}$ would represent a total load of $2000 \mathrm{~N}$. No slip boundary conditions were

150 applied to the proximal end of the implant.

151

152 The materials were obtained from the manufacturer. The radial component was made from a 153 cast CoCr alloy (ASTM standard F75, ISO standard 5832-4), the carpal plate component was

154 made from titanium alloy (Ti-6AI-4V ELI, ASTM standard F136, ISO 5832-3) and the

155 polyethylene was made from UHMWPe (ASTM Standard 648, ISO Standard 5834-1 +2).

156 The material properties can be seen in Table 1.

157

\begin{tabular}{|l|l|l|l|l|l|}
\hline Material & Modulus & Yield & Tensile strength & Elongation [\%] & Poisson's ratio \\
\hline
\end{tabular}




\begin{tabular}{|l|l|l|l|l|l|}
\hline & {$[\mathrm{GPa}]$} & {$[\mathrm{MPa}]$} & {$[\mathrm{MPa}]$} & & \\
\hline $\mathrm{CoCr}$ & $207(220-234)$ & 450 & 655 & 8 & 0.31 \\
\hline Titanium & 113.8 & 970 & 1450 & 14 & 0.30 \\
\hline Cortical bone & 20 & & & & 0.2 \\
\hline Cancellous bone & 0.1 & & & & 0.25 \\
\hline
\end{tabular}

Table 1: Material properties

159 The polyethylene was modelled using the Bergstöm-Boyce model [23] and the material model was obtained from MCalibration (Veryst Engineering) and the model parameters fitted. The reported parameters for the polyethylene model can be seen in Table 2 .

\begin{tabular}{|l|l|l|}
\hline$\mu$ & $\lambda$ & $\mathrm{D}$ \\
\hline 24.45 & 1.486 & 0.004 \\
\hline
\end{tabular}

Table 2: Polyethylene material coefficients

164 The finite element model was solved using the implicit solver in Abaqus

\section{Mechanical testing}

The Universal2 implant was mechanical tested in two different ways. Firstly the external strains on the implant were measured using strain gauges and secondly the internal strain of the implant was measured using a Fiber Bragg Grating sensor. 
174 Strain gauges were placed on the radial stem of the implant and the polyethylene component.

175 The polyethylene component and the carpal component were glued together so that no

176 relative motion was allowed between those two components. The implant was placed in

177 uniaxial compression. The experimental setup and location of strain gauges can be seen in

178 Figures $2 \mathrm{a}$ and $2 \mathrm{~b}$.

179

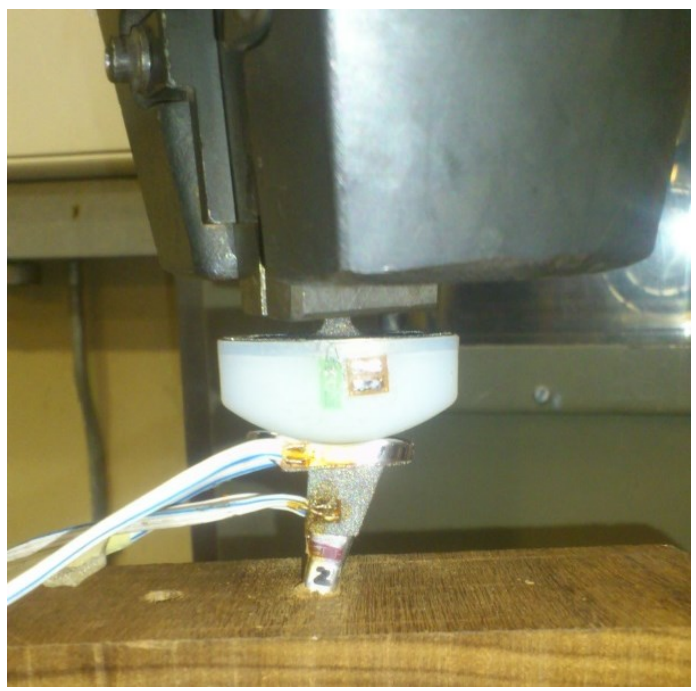

Figure 2a: Experimental setup of the

mechanical testing.

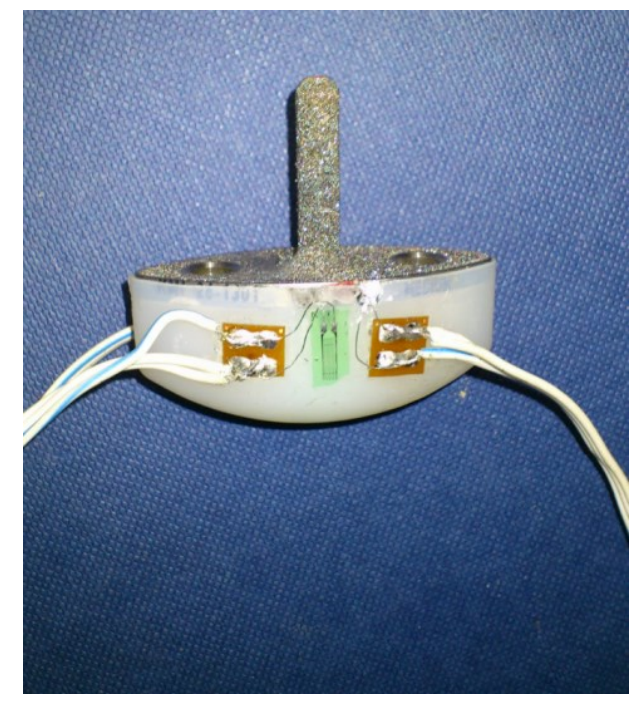

Figure 2b: Strain gauges applied onto the polyethylene component.

Strain data were collected at $100 \mathrm{~N}$ intervals with the total force ranging from 0 to $2000 \mathrm{~N}$.

Fiber Bragg Grating

The internal strain in the tested implant was additionally monitored using a Fiber Bragg Grating (FBG) sensor. An FBG being a periodic modulation of the refractive index within a section of an optical fibre, when illuminated by a broadband light, reflects a narrow set of wavelengths interfering with each other. The reflected spectrum can be approximated with a 
189 Gaussian, and the wavelength at the maximum reflection is denoted as Bragg wavelength, $\lambda_{B}$.

190 An FBG responds to both strain and temperature, and the resultant Bragg wavelength shift

191 can be described by the following equation:

192

$$
\frac{\Delta \lambda_{B}}{\lambda_{B}}=(1-p) \Delta \varepsilon+(\alpha+\xi) \Delta T
$$

where $p$ is the photo-elastic coefficient, $\alpha$ and $\xi$ are the thermal expansion and thermo-optic coefficients, respectively. For a standard FBG having the Bragg wavelength at $1550 \mathrm{~nm}$ the strain and temperature response coefficients are approximately $1.2 \mathrm{pm} / \mu \varepsilon$ and $10 \mathrm{pm} /{ }^{\circ} \mathrm{C}$, respectively.

A $1 \mathrm{~mm}$ diameter hole and $37 \mathrm{~mm}$ long was drilled into the proximal aspect of the stem of the radial component using an Electrical Discharge Machining (EDM) where the removal of the metal was carried out by using electrical discharge between an electrode and the implant.

This allowed for a long thin hole to be created having minimal effects on the structural integrity of the implant. The optical fibre was placed $37 \mathrm{~mm}$ into the stem from the proximal side. The fibre was cleaved so that the grating was located $2 \mathrm{~mm}$ away from the end, in order to obtain measurements as close as possible towards the end of the hole. The fibre was fixed using epoxy resin glue.

The prosthesis was implanted into a saw bone which was done by an orthopaedic surgeon allowing the optic fibre to run through the proximal aspect of the bone.

210 The experimental setup can be seen in Figure $3 \mathrm{a}$ and $3 \mathrm{~b}$. The implant was tested in a uniaxial compression with load increments of $100 \mathrm{~N}$ ranging from 0 to $800 \mathrm{~N}$. 


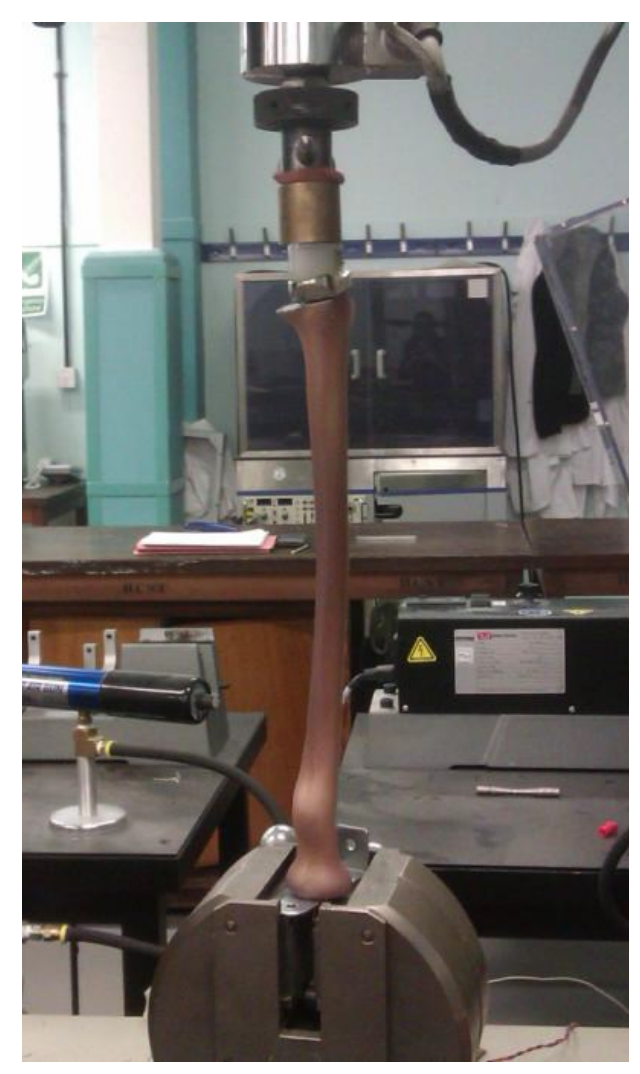

Figure 3a: Overview of the experimental

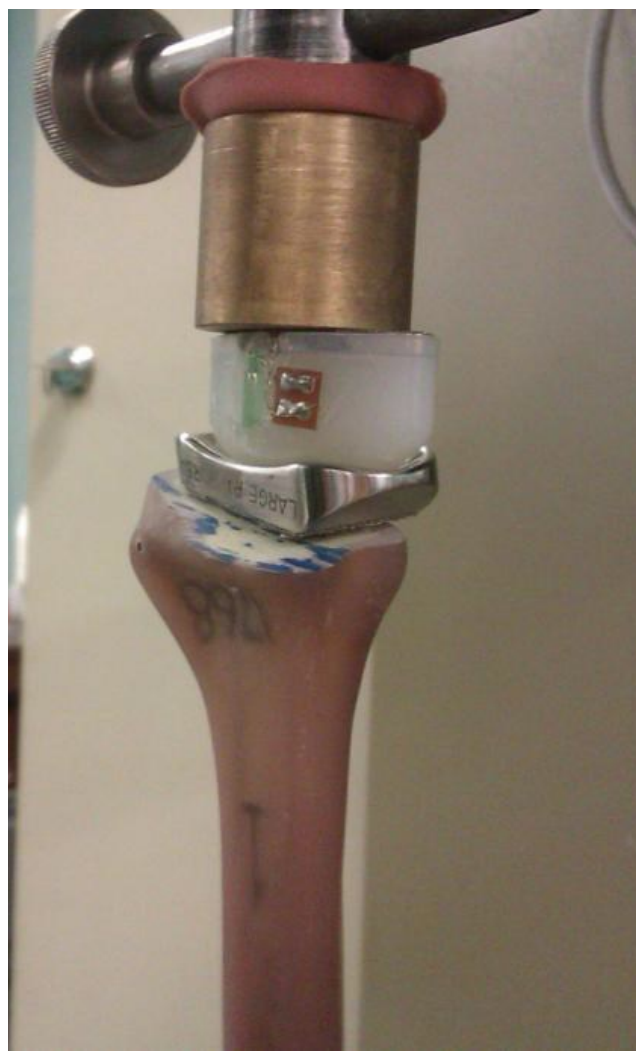

Figure 3b: Experimental setup

setup

\section{$214 \quad \underline{\text { Results }}$}

216 The finite element model was run under the given loading conditions. The stress distribution

217 was analysed and strain results were compared to the findings from the mechanical tests.

219 Finite element model

221 Figures $4 \mathrm{a}$ and $4 \mathrm{~b}$ show the stress distribution on the whole implant under compressive 222 loading of $2000 \mathrm{~N}$ and the strain distribution on the polyethylene component respectively. 


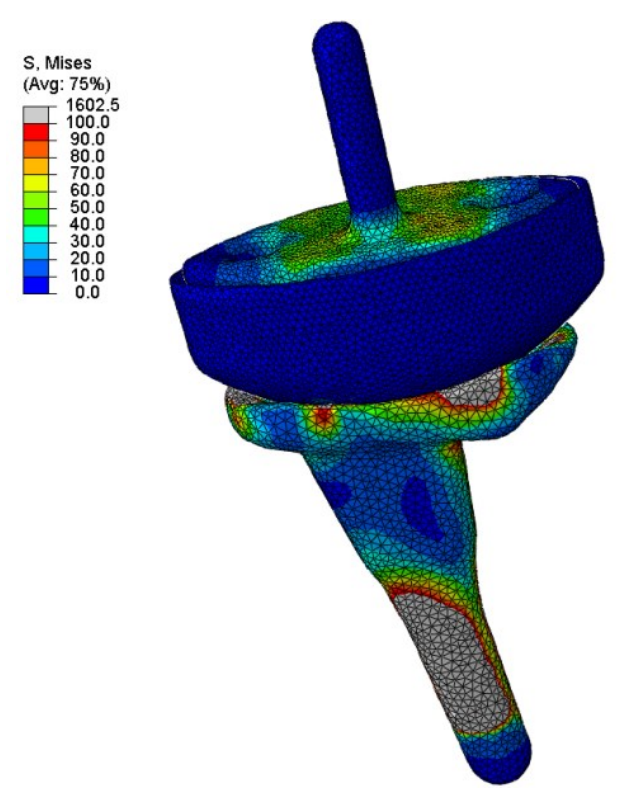

Figure 4a. Von Mises stress

distribution on the whole implant under compressive loading of $2000 \mathrm{~N}$

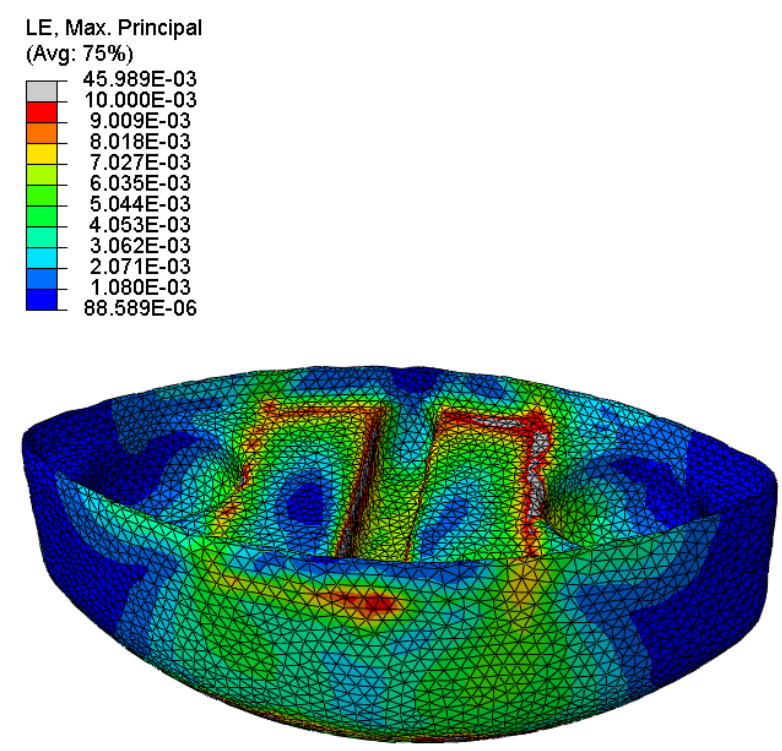

Figure 4b. Strain distribution on the polyethylene component under compressive loading of $2000 \mathrm{~N}$

225 From Figure 4a and 4b, it can be seen how the load applied on the carpal component is 226 transmitted through the radial component. The strains on the polyethylene component are 227 highest around the surface of the holes in which the carpal component articulates.

\section{Strain measurements on implant using strain gauges.}

231 Strain gauge values were read as a function of the applied load on the prosthesis. The load 232 was applied slowly and held for some time at each load interval. The results from the strain gauges were compared with the finite element model. The results from the strain measurements on the polyethylene and the computational predictions can be seen in Figure 5. 


\section{Calculated and measured strains in polyethylene}

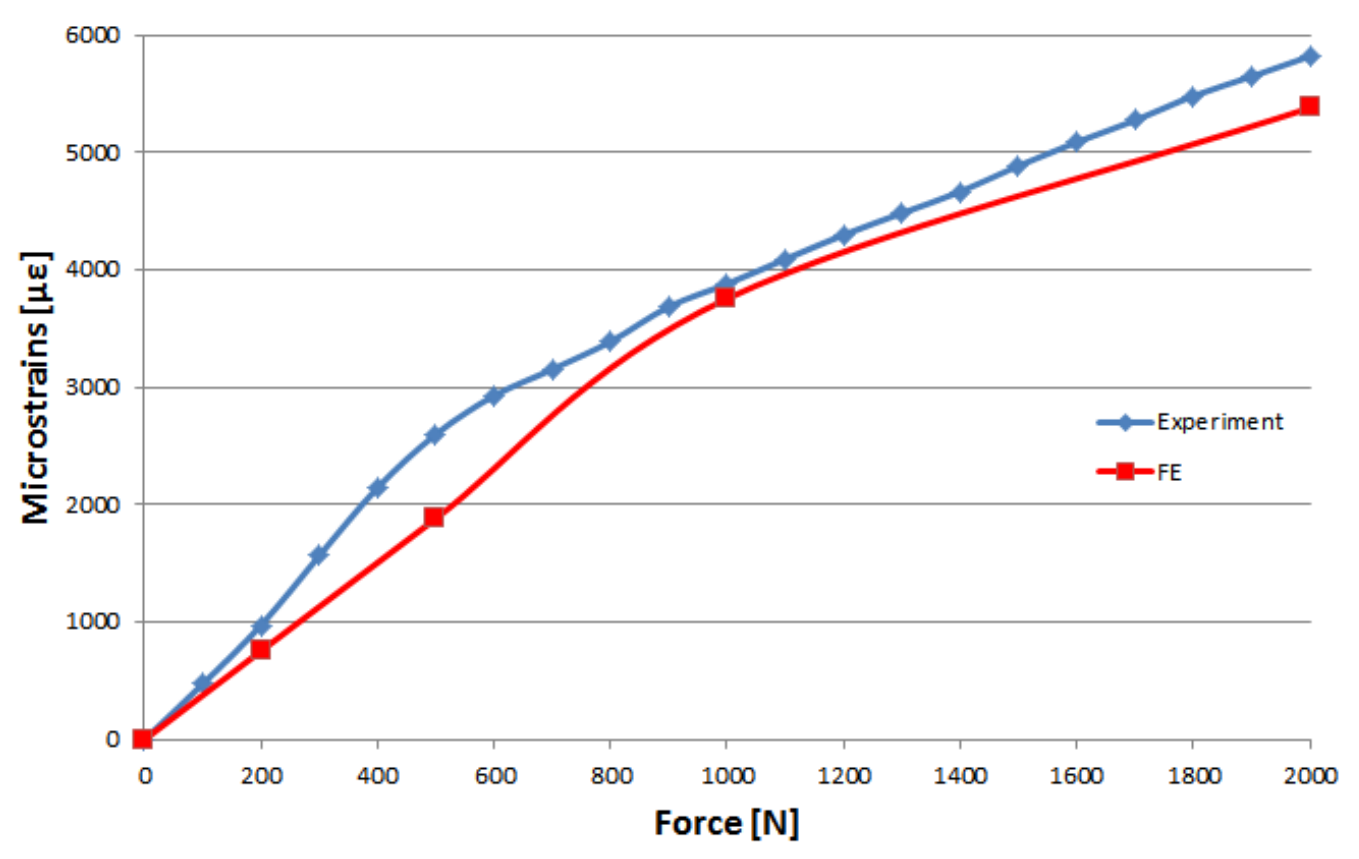

Figure 5: Strain as a function of load on the polyethylene component

237 Strain measurements were additionally obtained from the radial stem, with one strain gauge

238 applied towards the distal aspect of both dorsal and volar aspect of the radial component. The 239 results can be seen in Figure 6. 


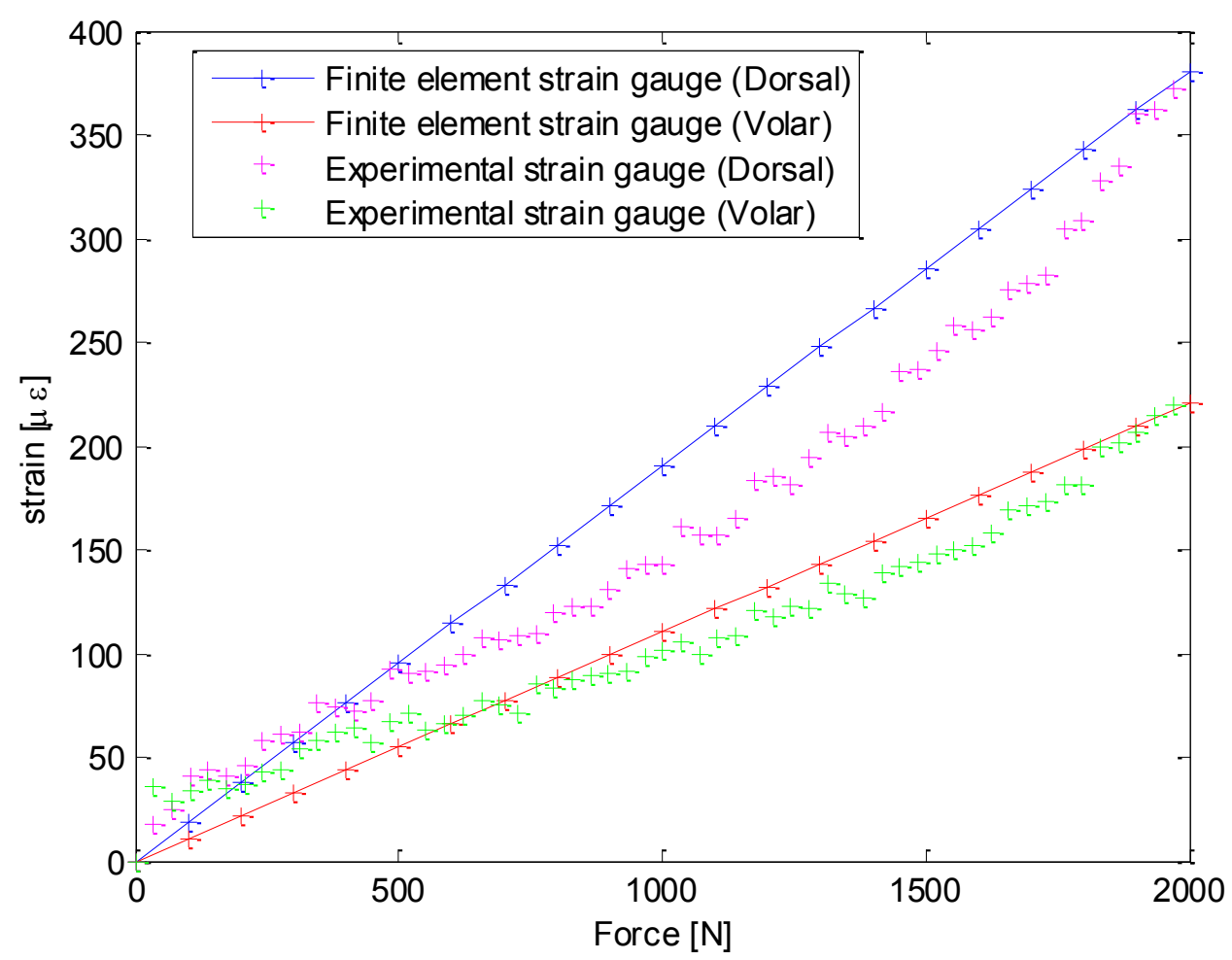

Figure 6: Strain measurements on the distal aspect of the radial component

242 Strain measurements on implant and saw bone using fibre Bragg grating

244 A node point was identified on the finite element part of the radial stem, corresponding to the

245 position of the fibre Bragg sensor within the implant. The results of the fibre Bragg grating

246 measurements were compared with the findings of the finite element model as can be seen in

247 Figure 7. 


\section{Comparison between experiments and FE modelling}

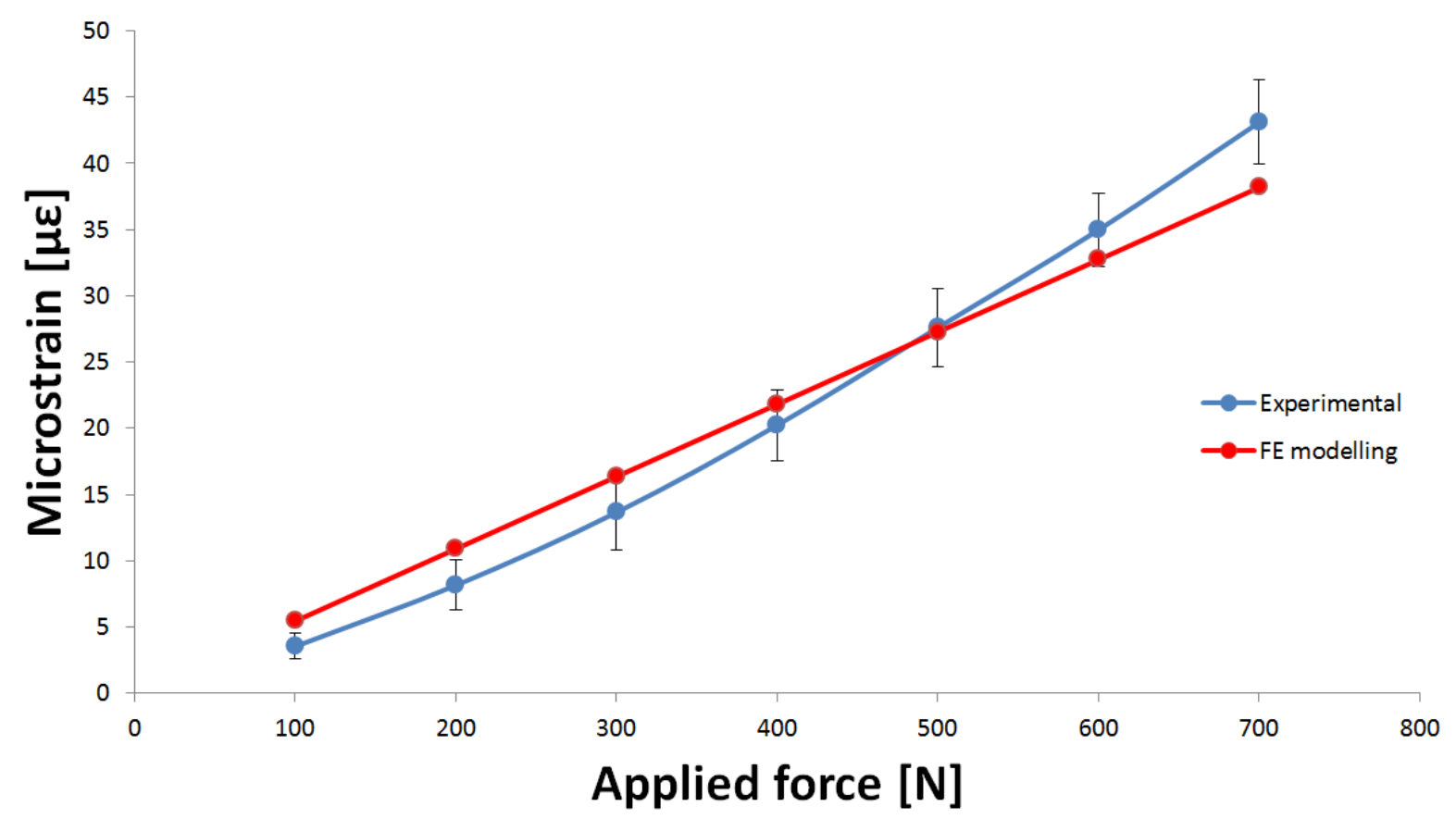

Figure 7: Comparison between Fiber Bragg Grating measurements and finite element model

\section{$\underline{\text { Discussion }}$}

Measuring the load transfer through a wrist implant in vivo is a difficult task. Bergmann et al [24] demonstrated that by placing force transducers inside a prosthesis, it is possible to measure the joint contact forces in larger joints such as the hip and the knee. Such implementation is difficult for the wrist given its small nature. Apart from biomechanical models, few studies have looked at the wrist loading of cadaveric specimens [25.26], but none at the loading of the implanted wrist as it is prone to buckling under uniaxial load in cadaveric specimens.

The presented work is the one of the first attempt to create a simplified finite element model of the implanted total wrist prosthesis in conjunction with experimental validation. The 
experimental work was carried out using a simplified uniaxial loading and compared with the findings from a finite element model. In-vivo loading conditions during gripping have been shown [9] to be a combination of proximally, dorsally and ulnarly (radially for the thumb) directed joint contact forces and therefore much more complex than the loads presented in this paper. However the overall magnitude of in-vivo joint contact force acting on the wrist is high and the mechanical trials aimed to simulate extreme loading conditions which are unlikely that patients with total wrist arthroplasty are able to generate. It is however important to understand how the implants behave under a simplified mechanical loading to further understand how they are going to behave under the more complex in-vivo loading and boundary conditions. For the stand alone experiment, the prosthesis was fixed on the proximal aspect of the radial component, whereas for the fibre Bragg experiment the implant was placed into a saw bone to try to mimic in-vivo fixation. From the experimental results it can be seen that the dorsal aspect of the prosthesis experiences higher loading than the volar aspect which partially can be explained by the volar offset of the geometry of the stem. From Figure 6, it can be seen that the results from the finite element model are in good agreement with the volar strain gauge, although the model over predicts the strain on the dorsal side. The measured strain values from the polyethylene component also demonstrated a good agreement with the experimental results. It can be argued that using the Bergström-Boyce material model will give accurate results, when used to model polyethylene orthopaedic materials.

281 From the strain gauge and the fibre Bragg grating measurements on the radial component, it 282 can be seen, by comparing the strain levels in Figure 6 to the ones in Figure 7, that the strain 283 decreases towards the centre of the radial stem. The total load for the implanted prosthesis was $800 \mathrm{~N}$ compared to the $2000 \mathrm{~N}$ for the stand alone prosthesis, which was due to the fragility of the optical fibre and the presence of bending loads in the experimental setup. 
286 From the Fibre Bragg data, hysteresis in conjunction with a non-linear strain curve was seen

287 in the experimental results which can be explained by the interaction between the optic fibre,

288 the epoxy resin to which it was attached and the metal implant. However the overall trend is

289 well in agreement with the results of the finite element model. Using the Fibre Bragg method

290 gives experimental results in locations that otherwise would have been impossible to reach

291 using strain gauges and therefore can give more in depth analysis of the three-dimensional

292 strain field within the prosthesis.

293 From table 1, it can be estimated that the proportionality of the strain for the cobalt chrome is around $3100 \mu \varepsilon$ but the maximum strain around the surface was measured and calculated to be around $380 \mu \varepsilon$ under $2000 \mathrm{~N}$ compressive load. This demonstrates that the strains on the radial stem are substantially lower than the yield limit and that the stem would be unlikely to fracture in vivo, even though subjected to more complex multi-axial loading scenario. The model does though not take into account poor bone material quality as can be seen in some patients, making proximal and distal fixation a greater challenge. However more research is needed to understand the load mechanics of the prosthesis in-vivo and to quantify the overall loading the whole implant is exposed to during activities of daily living of total wrist implant patients. Future work will incorporate a full three dimensional modelling of the implanted wrist to obtain further information about the load transfer characteristics of the Universal 2 wrist implant subjected to multi-axial loading.

\section{$\underline{\text { Limitations }}$}

307 There are many limitations to the presented study, in particular how the loading is applied as well as other boundary conditions. The modelling and testing does not incorporate the implant interaction with human bone. The bone quality will vary with each patient and poor 
310 bone quality will difficulty in fixation which were not incorporated into the model. The

311 model only looks at the loading in a steady state but doesn't incorporate any time dependent

312 loading behaviour. A full detailed convergence study was not performed on the number of

313 elements, due to the fact that orphan meshes were used to construct the model and changing

314 the element density would require a new model for each case. However a small comparison

315 between a finer mesh model and a coarser mesh model was made and based on the results it

316 was assumed that the element density presented in the paper was sufficient to obtain accurate 317 results.

318

319 Acknowledgements

320 The authors would like to thank Mr. Juan Fuente Gonzalez and the staff at the University of

321 Strathclyde's Advanced Forming Research Centre for the help of scanning and creating three 322 dimensional models from the Universal 2 implant. 


\section{References}

1. Swanson A. Flexible implant arthroplasty for arthritic disabilities of the radiocarpal joint. A silicone rubber intramedullary stemmed flexible hinge implant for the wrist joint, Orthop Clin North Am., 1973 , 4(2), pp:383-94.

2. Jolly SL, Ferlick DC, Clayton ML, Dennis DA, Stringer EA. Swanson silicone arthroplasty of the wrist in rheumatoid arthritis: A long-term follow-up, Journal of Hand Surgery, 1992, 17(1), pp:142-149.

3. Volz RG. Clinical experience with a new total wrist prosthesis, Archiv für orthopädische un Unfall Chirurgie, 1976, 85, pp: 205-209.

4. Meuli HC, Meuli total wrist arthroplasty, Clinical Orthopaedic Related Research, 1984, 187, pp:107-111.

5. Sheperd DET and Johnstone AJ. D. A new design concept for wrist arthroplasty, Mechanical Engineering and Physics, 2002, 24, pp: 641-650.

6. Sheperd DET and Johnstone AJ. D. Design considerations for a wrist implant, Proc. IMechE Part H, Engineering in Medicine, 2005, 219, pp: 43-52.

7. Fowler N and Nicol AC. A biomechanical analysis of the rheumatoid index finger after joint arthroplasty, Clinical Biomechanics, 2002, 17, pp:400-405.

8. Kanellopolous A. Three dimensional biomechanics of the hand and wrist in precision grip, 2011, PhD thesis, University of Strathclyde, Glasgow, UK.

9. Gislason M, Nash DH, Nicol AC, Kanellopoulos A, Bransby-Zachary M, Hems TEJ, Condon B, Stansfield B. A three dimensional finite element model of maximal grip loading in the human wrist, Proc. IMechE Part H, Engineering in Medicine, 2009, 223 (H7), pp:849-862. 
10. Chadwick EKJ and Nicol AC. Elbow and wrist joint contact forces during occupational pick and places activities. Journal of Biomechanics, 2000, 33, pp:591600.

11. Fok KS and Chou SM. Development of a finger biomechanical model and its considerations, Journal of Biomechanics, 2010, 43, pp:701-713.

12. Aitchison GA, Hukins DWL, Parry JJ, Shepherd DET, Trotman SG. A review of the design process for implantable orthopaedic medical devices, The Open Biomedical Engineering Journal, 2009, 3, pp:21-27.

13. Grosland N, Rogge RD, Adams BD. Influcence of articular geometry on prosthetic wrist stability, Clin Orthop Rel, Res, 2004, No 421, pp: 134-142.

14. Knight LA, Pal S, Coleman JC, Bronson F, Haider H, Levine DL, Taylor M, Rullkoetter PJ. Comparison of long-term numerical and experimental total knee replacement wear during simulated gait loading, Journal of Biomechanics, 2007, 40, pp: $1550-1558$.

15. Martelli S, Taddei F, Cristofolini L, Schileo E, Rushton N, Viceconti M. A new hip epiphyseal prosthesis: Design revision driven by a validated numerical procedure, Medical Engineering and Physics, 2011, 33, pp: 1203-1211.

16. Prendergast P. Finite element models in tissue mechanics and orthopaedic implant design, Clinical Biomechanics, 1997, 12(6), pp: 343-366.

17. McCullough MBA. Clinical and biomechanical analysis of total wrist arthroplasty devices, 2006, PhD thesis, University of Iowa, Iowa, USA.

18. McCullough MB, Adams BD, and Grosland NM. The Effect of Articular Surface Shape and Tendon Forces of Total Wrist Arthroplasty Systems: A Finite Element Study. Journal of Musculoskeletal Research Volume 15(4), 2012. 
19. Bajuri MN, Kadir MRA, Murali MR, Kamarul T. Biomechanical analysis of the wrist arthroplasty in rheumatoid arthritis: a finite element analysis, Medical and Biological Engineering and Computing, 2013, 51(1), pp:175-186.

20. Liu RM, Liang DK., Asundi A. Small diameter fibre Bragg gratings and applications, Measurement, 2013, 46, pp: 3440-3448.

21. Fresvig T, Ludvigsen $P$, Steen $H$, Reikerås. Fiber optic Bragg grating sensors: An alternative method to strain gauges for measuring deformation in bone, Medical Engineering and Physics, 2008, 30, pp:104-108.

22. Mohanty L, Tjin SC, Lie DTT, Panganiban SEC, Chow PKH. Fiber grating sensor for pressure mapping during total knee arthroplasty, Sensors and Actuators A, 2007, 135, pp: 323-328.

23. Bergström JS and Boyce MC. Constitutive modelling of the time-dependent and cyclic loading of elastomers and application to soft biological tissues. Mechanics of Materials, 2001, 33, pp: 523-530.

24. Bergmann G, Deuretzbacher G, Heller M, Graichen F, Rohlmann A, Strauss J, Duda GN. Hip contact forces and gait patterns from routine activities, Journal of Biomechanics, 2001, 34, pp:859-871.

25. Palmer A and Werner FW. Biomechanics of the distal radioulnar joint, Clinical Orthopaedics and Related Research, 1984, 187, pp: 26-35.

26. Pfaeffle HJ, Fischer KJ, Manson TT, Tomaino MM, Herndon JH, Woo S. A new methodology to measure load transfer through the forearm using multiple universal force sensors, Journal of Biomechanics, 1999, 32, pp: 1331-1335. 